\title{
From Research to Practical Application: A comment*
}

\author{
by Gerhard Laskowski**
}

This comment concerns measures adopted in the Federal Republic of Germany to guarantee the population's old-age pension benefits, not only in the short-term but above all in the long-term. As in all industrial countries, such measures have become necessary as a result of demographic trends, that is, the foreseeable increase in the percentage of old people, accompanied by a dramatic decline in the birth rate. Whereas there are still three people of working age in the Federal Republic today for every person older than 60 , model calculations have shown that in the year 2030 there will only be one person of working age for every senior citizen. For the statutory old-age pension scheme - the so-called "first pillar" of the old-age pension system - this means that the rate of contribution, which is currently almost $19 \%$ of earned income, would have to be approximately doubled by the year 2030 unless pension benefits are halved by that date. Neither one extreme solution, viz. doubling the rate of contribution, nor the other - having pension benefits - is feasible for a variety of reasons.

Compromises have to be sought, particularly those that have the least negative impact on pension levels in relation to earned incomes. Yet if we are to ease the pension burden that is going to increase dramatically in the coming decades, it is clear that the only effective solution is to extend the actual lifetime working period.

Which is why the Geneva Association is addressing this subject under the general heading of "THE FOURTH PILLAR". Such an idea - extending the lifetime working period - that is, raising the age limits for retirement, would seem to be incomprehensible for most people in the Federal Republic of Germany today in view of the almost two million unemployed in that country. The need to extend the lifetime work period will in fact only become urgent after the turn of the millenium. Therefore we have to consider already today what steps must be taken, and at what intervals, to prepare a large group of older people for a fundamental change in their lifestyle.

As we had only just begun to consider the question of a "Fourth Pillar" two years ago, two experts were commissioned to conduct a study entitled: "Extending the lifetime working period and creating a more gradual transition from working life to retirement, with a view to future labour-market and old-age pension provision requirements - Data and state of the debate in the Federal Republic of Germany”.

\footnotetext{
* Text presented at the Seminar of the "Geneva Association" organized by "CIRSA" Centro Italiano Ricerche e Studi Assicurativi) on October 11, 1989 in Milan.

** Gerling-Konzern, Köln
} 
The study was published about a year ago under the name of the Geneva Association.

The study done by W. Steinjan and J. Kruse addresses the question of whether and how it is possible to extend the lifetime working period and what impact any extension will have on the labour market. A flexible transition from working life to retirement is acknowledged to be an instrument for extending lifetime working in actual practice. Any form of a reduced working period at the end of a person's working life is regarded as a gradual transition from working life to retirement, in conjunction with a partial pension paid by the statutory old-age pension scheme.

A flexible system of this kind does not exist at present in the Federal Republic. Although it is true that options do exist today whereby a pension may be drawn upon early retirement, they presuppose as a matter of principle that the senior citizen has ended his or her working life. Early retirement - in its present form - must be regarded essentially as a measure for preventing the number of unemployed from rising even further. In the 1990's, however, the trend will be reversed as a result of radical demographic change. The number of employable people will decrease. It will then appear desirable, if not necessary, to increase the lifetime working period. It is clear that there are only two possible ways of extending working life: either the periods young people spend undergoing training have to be shortened - but there is certainly very little leeway here - or additional working time must be added at the end of people's working lives. The study is primarily concerned with the latter option and asks, inter alia, whether any obstacles exist, and if so which ones, to implementing this solution. A number of questions is asked:

- What does the population think of working life being extended?

- What is the situation regarding older people's mental and physical abilities?

- Can part-time jobs be provided for older people?

- What supporting measures can and should be taken by the legislator and the social partners, etc.?

The study concludes not only that there are no gerontological handicaps to prevent older people from staying on in gainful employment, but also that this is desirable for various reasons. Of course, more flexibility will be required not just from old workers but, logically enough, from employers and companies as well. A lengthy process of attitudechanging and re-organization will have to be allowed for here.

But the present rigid age limits can and should not only be raised. This in isolation would do nothing to change the regrettable situation whereby workers put in a full working day at the end of their last month in employment find themselves idle the next day. Raising the age limits only makes sense and will certainly only be feasible when additional provisions are introduced to facilitate the gradual transition to retirement. A gradual (or flexible) transition to retirement means that older workers would only do part-time work during this transition period.

A form of transition to retirement as described here is at present only found in isolated cases in the Federal Republic of Germany, viz. in some collective agreements and plant agreements. Mention could be made of the collective agreements in the cigarette and chemical industries and plant agreements within large internationally-renowned companies such as Siemens and Mercedes-Benz. On the other hand, the Federal Republic has hitherto had no provisions which provide for a partial pension to be paid by the statutory old-age 
pension scheme in addition to ensuring a gradual transition to retirement. This situation will soon change, however. The German legislator is currently preparing an amendment to the law, the details of which are presented later.

Our study starts from the assumption that the normal age limit - currently 60 years for women and 63 for men - will be raised substantially, for example to at least 65 . In addition, the transition phase to retirement should end not as early as 65 but at an older age, for example 67 or 70 years.

The study emphasizes, however, that fundamental problems occur with all models that are conceivable for a gradual transition and that these still have to be analyzed and solved. First of all, a substantial expansion of the labour market for part-time workers is needed, with attractive offers for older workers in particular. Secondly, provisions are required to determine the level of income that part-time workers will be allowed to earn on top of a partial pension as the latter would be designed to offset, or at least to partially offset, the loss of income resulting from a part-time job.

The study also indicates the way in which the creation of a "Fourth Pillar" would have to be supported by the legislator as well as by the social partners.

The authors show that the creation of a "Fourth Pillar" is a necessary measure to ensure the long-term financial viability of the old-age pension system. In their opinion, the essential features of a "Fourth Pillar" include the gradual, promptly-announced raising of the normal retirement age limit and the introduction of a partial pension in conjunction with a gradual transition from working life to retirement as a means of ensuring the practicable implementation of such an increase in age limits. The authors of the study did not set out to define and propose all the details of the way a fourth pillar would operate. Rather, their intention was to identify the problems, so that it would become clear what questions need answering, what matters need further research and what measures have to be taken to ensure that a fourth pillar is a success.

It is certainly a rare occurrence when experts' ideas coincide with the legislator's proposals; such a miracle has occurred in Germany!

Since March 1989 a draft bill has been in existence which will reform the statutory oldage pension scheme. It is sponsored not only by the government coalition, but also by the larger opposition party, the SPD, that is, by a broad parliamentary majority. The draft bill contains a whole series of reform measures, but three in particular, which may be said to put into practice what the Geneva Association means by the term "Fourth Pillar".

First, the age limits, which today are 60 and 63 years respectively, are to be raised in stages to 65 years between the year 2001 and 2012 - both for women and men - so that the different age limit for men and women will have been finally abolished by 2012 .

Secondly, the age limits will not be treated as rigid limits. People will have the option to draw their pensions both earlier and later, although early pensionable retirement will be limited to three years. The important feature compared with the present provisions is that an old-age pension which is drawn early will be reduced by an actuarial deduction, viz. by $0.3 \%$ per month, so that it will be reduced by $10.8 \%$ if drawn three years earlier. On the other hand, for every month that a senior citizen postpones drawing his or her pension after the age of 65 , the benefit will be increased permanently by $0.5 \%$. 
Thirdly, beneficiaries will also be able to draw partial pensions in place of the full pension and will at the same time be able to do a part-time job. Certain limits will apply to the income from this part-time job, depending on the amount of the pension. The provision concerning partial pensions is due to come into force as early as 1992. Although workers will not be granted any statutory entitlement to a part-time job, they will be entitled to negotiate such part-time work with their employers.

The present draft law and its 'raison d'être' show that the German legislator is now prepared to pave the way for creating a sound, long-term basis on which the statutory old-age pension scheme will be able to finance benefits.

The package of measures envisaged will considerably reduce the need to raise the contribution rates. In my introduction I mentioned that the current contribution rate of almost $19 \%$ of earned income would have to be practically doubled by the year 2030 if the envisaged reform measures, particularly the introduction of the "Fourth Pillar", were not taken. Model calculations by the Federal Ministry of Labour and Social Affairs show that if the planned amendments to the law are enacted, the applicable rate of contribution would only have to be increased to $27 \%$ of earned income by the year 2030 , whereas without these measures it would already amount to $36.4 \%$. A substantial part of the smaller increase in contributions is attributable to the influence of the fourth pillar, that is raising the age limit and at the same time introducing a partial pension.

It is gratifying to note that the initiatives and ideas of the Geneva Association concerning the creation of a "Fourth Pillar" in the Federal Republic of Germany have been reflected in a legislation with such surprising swiftness. 